\title{
Clinical Significance of the NQO1 C609T Polymorphism in Non Small Cell Lung Adenocarcinoma Patients
}

\author{
Mirza Masroor ${ }^{1 \&}$, Amit Jain ${ }^{1 \&}$, Jamsheed Javid³, Rashid Mir ${ }^{3}$, Y Prashant ${ }^{1}$, A \\ Imtiyaz $^{1}$, Z Mariyam ${ }^{1}$, Anant Mohan ${ }^{2}$, PC Ray ${ }^{1}$, Alpana Saxena ${ }^{1 *}$
}

\begin{abstract}
Background: $\mathrm{NAD}(\mathrm{P}) \mathrm{H}$ :quinone oxidoreductase 1 (NQO1) is part of the antioxidant defence system involved in detoxification. This study aimed to analyze the influence of NQO1 (C609T) genetic polymorphism in non small cell lung cancer (NSCLC)as a putative risk factor. Materials and Methods: Present study included 100 cases of NSCLC (adenocarcinoma) patients and 100 age and sex matched healthy controls. NQO1 (C609T) genotyping was performed by allele specific PCR for assessment of putative associations with clinical outcome and genotypes of. The association of the polymorphism with the survival of NSCLC patients' was analyzed by Kaplan-Meier method. Results: In Indian NSCLC (adenocarcinoma) patients increased risk of developing NSCLC was found to be associated with NQO1 609TT genotype [OR 3.68(0.90-14.98), RR 2.04(0.78-5.31)] for CT [OR 2.91(1.585.34), RR 1.74(1.23-2.44) $p=0.0005$ for CT], for CT+TT [ OR 3.26(1.82-5.82), RR 1.87(1.34-2.61) $p<0.0001$ for $\mathrm{CT}+\mathrm{TT}]$. A significant difference $(\mathrm{p}=\mathbf{0 . 0 0 0 9})$ was observed in genotype distribution among cases and healthy controls. Patients with CT+TT genotype exhibited a significant poor overall survival compared with patients displaying homozygous $\mathrm{CC}$ genotype $(\mathrm{p}=\mathbf{0 . 0 3})$ and when survival independently compared with $\mathrm{CC}$, $\mathrm{TT}$ and CT genotype was also found to be significantly associated $(p=0.02)$. Overall median survival times were $C$ T 6.0 months, TT 8.2 months, and CT + TT (6.4 months)]. Conclusions: The present study revealed that NQO1 CT, TT and CT+TT genotypes may be associated with clinical outcome and risk of developing NSCLC in the Indian population.
\end{abstract}

Keywords: NSCLC patients - adenocarcioma - NQO1 gene (C609T) polymorphism - AS-PCR.

Asian Pac J Cancer Prev, 16 (17), 7653-7658

\section{Introduction}

NAD (P) H: quinone oxidoreductase 1 (NQO1) is involved in antioxidant defence system by detoxification of mutagenic agents and carcinogenic quinones by two electron reduction to hydroquinones (Chen et al., 1999; Hou et al., 2005). NQO1 protects cells from quinones damage by reducing mutagenic and carcinogenic agents and competing for them with $\mathrm{p} 450$ reductase to prevent highly reactive semiquinone production (Sarmanova et al., 2004). NQO1 protects cells from oxidative stress by maintaining antioxidant forms of ubiquinone and vitamin $\mathrm{E}$ and this enzymatic activity could be enough to protect against carcinogenesis (Chen et al., 1999; Hou et al., 2005). NQO1 gene is mapped on chromosomal 16 location q22.1 and comprised of 6 exons and 5 introns (Guha et al., 2008). NQO1 is a flavoprotein which functions as a homodimer. The physiological dimer has one catalytic site per monomer. Each monomer consists of 273 amino acids. NQO1 is expressed in human epithelial and endothelial tissues and at high levels in many human solid tumors. NQO1 is a cytosolic enzyme, localized in smaller amounts to mitochondria, endoplasmic reticulum and nucleus (Ross et al., 2004; Chao, 2006). C to T Polymorphism at position 609 of exon 6 of the NQO1 that encodes for a proline to serine substitution at position 187 in the amino acid sequence of the protein. Proline to Serine amino acid substitution leads to an extremely unstable NQO1 protein which is rapidly ubiquitinated and degraded by the proteasome (Siegel et al., 2001). Some studies have found that the C609T SNP is associated with an increased risk for several malignancies, eg, colorectal cancer, breast cancer, lung cancer, and bladder cancer (Chao, 2006; Chen, 2012). NAD(P)H:quinone oxidoreductase 1 (NQO1), also known as diphtheria toxin diaphorase (DT-diaphorase), is a cytoplasmic 2-electron reductase, belonging to the NAD(P)H dehydrogenase (quinone) family. NQO1 plays an important role in the aromatic amine metabolism pathway (Menashe et al., 2012). The CC genotype of the NQO1 C609T polymorphism is associated with the risk

${ }^{1}$ Biochemistry, Maulana Azad Medical College, ${ }^{2}$ Department of Pulmonary Medicine and Sleep Disorder All India Institute of Medical Sciences, New Delhi, India, ${ }^{3}$ Department of Medical Laboratory Technology, Faculty of Applied Medical Sciences, University of Tabuk, Tabuk, Saudi Arabia \&Equal contributors*For correspondence: biochempublications@gmail.com 
of lung cancer, and that the TT genotype increases the risk of smoking for cancers of the esophagus and lung (Hamajima et al., 2002).

Thus present study aimed to conduct a case-control study to evaluate the relevance of the NQO1 (C609T) polymorphism on the risk and susceptibility of NSCLC in Indian patients.

\section{Materials and Methods}

\section{Cases and controls}

Present study included 100 newly diagnosed NSCLC (Adenocarcinoma) patients and 100 gender and age $( \pm 5$ years) matched healthy controls. $3 \mathrm{ml}$ Peripheral blood sample collected from each subjects included in the study. This study was approved by the Institutional Ethics Committee of MAMC, New Delhi and written informed consent was obtained from all subjects. Patient follow-up was obtained through the hospital records and follow-up done from May 2013 to February 2015.

\section{DNA extraction and genotype}

Genomic DNA extraction was done by phenol chloroform method from blood samples collected in EDTA vials from cases as well as controls. The C609T polymorphism was performed by allele specific PCR method with NQO1 C609 Forward 5' TAT CAG AGT GTC TTA CTG AGA 3', NQO1C609 Reverse 5' AAT GCT ATA TGT CAG TTG AGG 3'and NQO1T609 Forward 5' GTG GCT TCC AAG TCT TAG AAT3', NQO1T609 Reverse 5' TTT CTA GCT TTG ATC TGG TTG3' (Haruya et al., 2003). PCR was performed in $25 \mu \mathrm{l}$

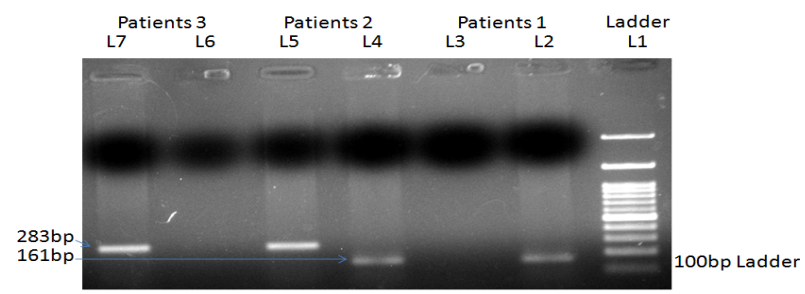

Figure 1. PCR Amplification of Normal and Mutant Alleles of NQO1 (C609T) Polymorphism; by Allele Specific PCR Method. L1:100bp ladder. Patient1; L2 - L3: Normal allele (C) amplified: Patients 1 positive for Homozygous $\mathrm{C}$ allele. Patient2; L4 - L5: Both normal (C) and mutant allele (T) amplified: Patients 2 positive for Heterozygous $\mathrm{C}$ and $\mathrm{T}$ allele. Patient3; L6 - L7: Mutant allele (T) amplified: Patients3 Positive for Homozygous T allele
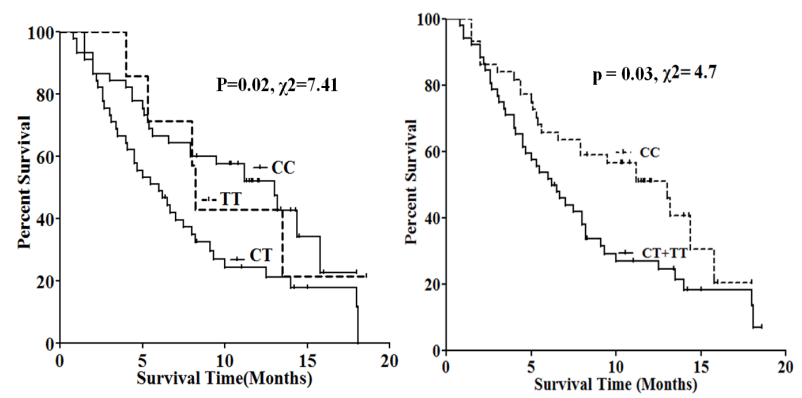

Figure 2. Kaplan-Meier Survival Curves of NSCLC Patients with Respect to NQO1 (C609T) Polymorphism reaction volume containing $3 \mu \mathrm{l}$ of $100 \mathrm{ng}$ template DNA, $0.25 \mu \mathrm{l}, 25 \mathrm{pmol}$ each primer $2.5 \mu \mathrm{l}, 10 \mathrm{mM}$ dNTPs, 1.5 $\mu \mathrm{l}$ of $20 \mathrm{mM} \mathrm{MgCl} 2,0.3 \mu \mathrm{l}$ of $5 \mathrm{U} / \mu \mathrm{l}$ Taq polymerase with $2.5 \mu \mathrm{l}$ of $10 \mathrm{X}$ Taq Buffer (Fermantas) and $14.7 \mu \mathrm{l}$ of nuclease-free $\mathrm{ddH}^{2} \mathrm{O}$. The PCR was performed with initial denaturation at $94^{\circ} \mathrm{C}$ for 10 minutes, followed by 40 cycles of denaturation at $95 \mathrm{oC}$ for 40 seconds, annealing at $55 \mathrm{oC}$ for 40 seconds, extension at $72^{\circ} \mathrm{C}$ for 40 seconds and the final extension was at $72^{\circ} \mathrm{C}$ for 10 minutes. PCR products were separated by electrophoresis on a $2 \%$ agarose gel containing ethidium bromide and the amplified sequences 161 base pairs for NQO1 609C and 283base pairs for NQO1 609T (Figure 1).

\section{Statistical analysis}

Genotype frequencies between the cases and controls were evaluated using the Chi square test, Hardy-Weinberg equilibrium test used to check the allele frequency and values below 5 were analyzed by Fisher exact test. The associations between NQO1T genotypes and risk of NSCL cancer (Adenocarcinoma) were estimated by computing the odds ratios (ORs), risk ratios (RRs) and risk differences (RDs) with $95 \%$ confidence intervals (CIs). Kaplan-Meier

Table 1. Distribution of selected characteristics among NSCLC patients and healthy controls

\begin{tabular}{|c|c|c|}
\hline Variables & $\begin{array}{c}\text { NSCLC } \\
\text { patients }(\%)\end{array}$ & $\begin{array}{c}\text { Healthy } \\
\text { controls }(\%)\end{array}$ \\
\hline $\begin{array}{l}\text { Total no. } \\
\text { Gender }\end{array}$ & 100 & 100 \\
\hline Males & 71 & 71 \\
\hline Females & 29 & 29 \\
\hline \multicolumn{3}{|c|}{ Age at diagnosis (Years) } \\
\hline$<55$ & 56 & 56 \\
\hline$>55$ & 44 & 44 \\
\hline $\begin{array}{l}\text { Mean + SD age } \\
\quad(\text { years })\end{array}$ & $\begin{array}{c}54.37+10.77 \\
\text { (range } 32-75 y e a r s)\end{array}$ & $\begin{array}{c}54.25+10.82 \\
\text { (range } 30-70 \text { years) }\end{array}$ \\
\hline \multicolumn{3}{|l|}{ Smoking status } \\
\hline Non smoker & 55 & 55 \\
\hline Smoker smokers & 45 & 45 \\
\hline Current smokers & 24 & 24 \\
\hline Ex-smokers & 21 & 21 \\
\hline \multicolumn{3}{|l|}{ Smoking type } \\
\hline Cig & 18 & 18 \\
\hline Bidi & 16 & 16 \\
\hline Hukka & 11 & 11 \\
\hline \multicolumn{3}{|c|}{ Smoking level (pack year) } \\
\hline Mild $(<10)$ & 23 & 23 \\
\hline Moderate $(<40)$ & 18 & 18 \\
\hline Heavy $(>40)$ & 4 & 4 \\
\hline \multicolumn{3}{|l|}{ TNM Stage } \\
\hline Early (I\&II) & 30 & \\
\hline Advanced (III\&IV) & 70 & \\
\hline \multicolumn{3}{|l|}{ Distant Metastases } \\
\hline Positive & 44 & \\
\hline Negative & 56 & \\
\hline \multicolumn{3}{|c|}{ Histopathological Grade } \\
\hline Grade 1 & 24 & \\
\hline Grade 2 & 41 & \\
\hline Grade 3 & 35 & \\
\hline \multicolumn{3}{|l|}{ Pleural effusion } \\
\hline Yes & 15 & \\
\hline No & 85 & \\
\hline
\end{tabular}


Clinical Significance of the NQO1 C609T Polymorphism in Non Small Cell Lung Cancer Patients

methods were used to evaluate the relationship between NQO1 genotype and overall survival of NSCLC patients. All statistical analyses were performed using Graph Pad Prism 6.0 or SPSS 16.0.

\section{Results}

Study population:

All demographic features of the subjects are depicted (Table 1). In brief, total of 100 Non-small cell lung adenocarcinoma patients and same number of healthy control were analyzed.

Both cases and controls include 71 males and 29 females of age $<55$ group (56\%) and $>55$ group (44\%) with mean $\pm \mathrm{SD}$ in cases of $54.37+10.77$ (range $32-75$ years) and controls of $54.25+10.82$ (range $30-70$ years). $44 \%$ patients were in stage IV, $15 \%, 15 \%$ and $26 \%$ patients in stage I, II and III respectively while $44 \%$ patients had distant metastases. Patients with different pathological grade, grade 1 (well differentiated) includes $24 \%$, grade

Table 2. Genotype frequencies of NQO1 (C609T) among NSCLC Cases and Controls

\begin{tabular}{lcccccc}
\hline Variables & CC & CT & TT & p value & $\begin{array}{c}\text { C allele } \\
\text { frequency }\end{array}$ & $\begin{array}{c}\text { T allele } \\
\text { frequency }\end{array}$ \\
\hline Patients $(\mathrm{n}=100)$ & $45(45 \%)$ & $48(48 \%)$ & $7(7 \%)$ & 0.0009 & 0.69 & 0.31 \\
Controls(n=100) & $71(71 \%)$ & $26(26 \%)$ & $3(3 \%)$ & & 0.84 & 0.16 \\
\hline
\end{tabular}

Table 3. NQO1 Genotype Frequencies in Cases \& Controls and Associations with NSCLC Risk

\begin{tabular}{lccccr}
\hline NQO1 & Control & $\begin{array}{c}\text { Cases } \\
(\mathrm{n}=100)\end{array}$ & OR*(95\% CI $)$ & RR** & P value \\
\hline CC & 71 & 45 & Ref $(1)$ & 1 & \\
TT & 3 & 7 & $3.68(0.90-14.98)$ & $2.04(0.78-5.31)$ & 0.09 \\
CT & 26 & 48 & $2.91(1.58-5.34)$ & $1.74(1.23-2.44)$ & 0.0005 \\
CT+TT & 29 & 60 & $3.26(1.82-5.82)$ & $1.87(1.34-2.61)$ & $<0.0001$ \\
\hline
\end{tabular}

Table 4. Association and Stratification Analysis of NQO1 (C609T) Polymorphism and NSCLC

\begin{tabular}{|c|c|c|c|c|c|c|}
\hline Variables & Total & $\begin{array}{c}\text { CC Genotype } \\
\mathrm{n}(\%)\end{array}$ & $\begin{array}{c}\text { CT Genotype } \\
\mathrm{n}(\%)\end{array}$ & $\begin{array}{l}\text { TT Genotype } \\
\text { n (\%) }\end{array}$ & $\begin{array}{l}\mathrm{C} \text { allele } \\
\text { frequency }\end{array}$ & $\begin{array}{l}\mathrm{T} \text { allele } \\
\text { frequency }\end{array}$ \\
\hline \multicolumn{7}{|l|}{ Gender } \\
\hline Male & 71 & $34(47.9 \%)$ & $33(46.5 \%)$ & $4(5.6 \%)$ & 0.5 & 0.5 \\
\hline Female & 29 & $11(37.9 \%)$ & $15(51.7 \%)$ & $3(10.4 \%)$ & 0.18 & 0.82 \\
\hline \multicolumn{7}{|l|}{ Age (in years) } \\
\hline$<55$ & 56 & $27(48.22 \%)$ & $26(46.43 \%)$ & $3(5.35 \%)$ & 0.4 & 0.6 \\
\hline$>55$ & 44 & $18(40.90 \%)$ & $22(50 \%)$ & $4(9.1 \%)$ & 0.29 & 0.71 \\
\hline \multicolumn{7}{|l|}{ Smoking status } \\
\hline Nonsmokers & 55 & $29(52.7 \%)$ & $21(38.1 \%)$ & $5(9.2 \%)$ & 0.39 & 0.61 \\
\hline Smokers & 45 & $16(35.5 \%)$ & $27(60 \%)$ & $2(4.5 \%)$ & 0.29 & 0.71 \\
\hline Current Smokers & 24 & $10(41.6 \%)$ & $13(54.1 \%)$ & $1(4.2 \%)$ & 0.17 & 0.83 \\
\hline Ex-smokers & 21 & $6(28.5 \%)$ & $14(66.6 \%)$ & $1(4.83 \%)$ & 0.13 & 0.87 \\
\hline \multicolumn{7}{|l|}{ Smoking type } \\
\hline Cigarette & 18 & $7(38.8 \%)$ & $9(50 \%)$ & $2(11.2 \%)$ & 0.64 & 0.36 \\
\hline Bidi & 16 & $4(25 \%)$ & $12(75 \%)$ & $0(\%)$ & 0.63 & 0.38 \\
\hline Hukka & 11 & $5(45.5 \%)$ & $6(54.5 \%)$ & $0(\%)$ & 0.73 & 0.27 \\
\hline \multicolumn{7}{|c|}{ Smoking level (pack year) } \\
\hline $\operatorname{Mild}(<10)$ & 23 & $10(43.5 \%)$ & $13(56.5 \%)$ & $0(\%)$ & 0.72 & 0.28 \\
\hline Moderate $(<40)$ & 18 & $3(16.6 \%)$ & $13(72.2 \%)$ & $2(11.2 \%)$ & 0.53 & 0.47 \\
\hline $\operatorname{Heavy}(>40)$ & 4 & $3(75 \%)$ & $1(25 \%)$ & $0(\%)$ & 0.58 & 0.42 \\
\hline \multicolumn{7}{|l|}{ TNM Stage } \\
\hline Early (I\&II) & 30 & $19(63.3 \%)$ & $10(33.4 \%)$ & $1(3.3 \%)$ & 0.8 & 0.2 \\
\hline Advanced (III\&IV) & 70 & $26(37.1 \%)$ & $38(54.3 \%)$ & $6(8.6 \%)$ & 0.64 & 0.36 \\
\hline \multicolumn{7}{|l|}{ Distant Metastases } \\
\hline Positive & 44 & $17(38.6 \%)$ & $23(52.3 \%)$ & $4(9.1 \%)$ & 0.65 & 0.35 \\
\hline Negative & 56 & $28(50 \%)$ & $25(44.6 \%)$ & $3(5.4 \%)$ & 0.72 & 0.28 \\
\hline \multicolumn{7}{|l|}{ Histopathological Grade } \\
\hline Grade I & 24 & $5(20.8 \%)$ & $17(70.8 \%)$ & $2(8.4 \%)$ & 0.6 & 0.4 \\
\hline Grade II & 41 & $22(53.6 \%)$ & $16(39.1 \%)$ & $3(7.3 \%)$ & 0.73 & 0.27 \\
\hline Grade III & 35 & $18(51.4 \%)$ & $15(42.8 \%)$ & $2(5.8 \%)$ & 0.73 & 0.27 \\
\hline \multicolumn{7}{|l|}{ Pleural effusion } \\
\hline No & 85 & $41(48.2 \%)$ & $38(44.7 \%)$ & $6(7.1 \%)$ & 0.71 & 0.29 \\
\hline Yes & 15 & $4(26.7 \%)$ & $10(66.7 \%)$ & $1(6.6 \%)$ & 0.6 & 0.4 \\
\hline
\end{tabular}


Table 5. Association between the NQO1 genotype and Clinico-pathologic Characteristics in Cases

\begin{tabular}{|c|c|c|c|c|}
\hline $\begin{array}{l}\text { Variables } \\
\text { Gender }\end{array}$ & $\begin{array}{c}\text { Group I } \\
\text { Male }\end{array}$ & $\begin{array}{l}\text { Group II } \\
\text { Female }\end{array}$ & OR & $\mathrm{RR}$ \\
\hline $\mathrm{CC}$ & 34 & 11 & $\operatorname{Ref}(1)$ & \\
\hline $\mathrm{CT}$ & 33 & 15 & $1.4(0.56-3.5)$ & $1.09(0.85-1.41)$ \\
\hline $\mathrm{TT}$ & 4 & 3 & $2.31(0.44-12)$ & $1.32(0.68-2.56)$ \\
\hline Age (in years) & $<55$ & $>55$ & & \\
\hline $\mathrm{CC}$ & 27 & 18 & $\operatorname{Ref}(1)$ & \\
\hline $\mathrm{CT}$ & 26 & 22 & $1.26(0.55-2.89)$ & $1.1(0.77-1.57)$ \\
\hline TT & 3 & 4 & $2(0.39-10.02)$ & $1.4(0.57-3.4)$ \\
\hline Smoking status & Non-smokers & Smokers & & \\
\hline $\mathrm{CC}$ & 29 & 16 & $\operatorname{Ref}(1)$ & \\
\hline CT & 21 & 27 & $2.33(1-5.37)$ & $1.47(0.99-2.17)$ \\
\hline $\mathrm{TT}$ & 5 & 2 & $0.72(0.12-4.17)$ & $0.9(0.53-1.51)$ \\
\hline Smoking status & Current Smokers & Ex-smokers & & \\
\hline $\mathrm{CC}$ & 10 & 6 & $\operatorname{Ref}(1)$ & \\
\hline $\mathrm{CT}$ & 13 & 14 & $1.79(0.50-6.34)$ & $1.29(0.75-2.23)$ \\
\hline TT & 1 & 1 & $1.66(0.08-31.89)$ & $1.25(0.29-5.26)$ \\
\hline Smoking type & Cigarette & Bidi + Hukka & & \\
\hline $\mathrm{CC}$ & 7 & 9 & $\operatorname{Ref}(1)$ & \\
\hline $\mathrm{CT}$ & 9 & 18 & $1.55(0.43-5.54)$ & $1.31(0.60-2.83)$ \\
\hline TT & 2 & 0 & $0.15(0.00-3.81)$ & $0.43(0.25-0.76)$ \\
\hline Smoking level (pack year) & $\operatorname{Mild}(<10)$ & $\operatorname{Moderate}(<40)+\operatorname{Heavy}(>40)$ & & \\
\hline $\mathrm{CC}$ & 10 & 6 & $\operatorname{Ref}(1)$ & \\
\hline $\mathrm{CT}$ & 13 & 14 & $1.79(0.50-6.34)$ & $1.29(0.75-2.23)$ \\
\hline TT & 0 & 2 & $8.07(0.33-196.3)$ & - \\
\hline TNM Stage & Early (I\&II) & Advanced (III\&IV) & & \\
\hline $\mathrm{CC}$ & 19 & 26 & $\operatorname{Ref}(1)$ & \\
\hline CT & 10 & 38 & $2.77(1.11-6.92)$ & $2.02(1.05-3.87)$ \\
\hline $\mathrm{TT}$ & 1 & 6 & $4.38(0.48-39.52)$ & $2.95(0.46-18.74)$ \\
\hline Distant Metastases & Positive & Negative & & \\
\hline $\mathrm{CC}$ & 17 & 28 & $\operatorname{Ref}(1)$ & \\
\hline $\mathrm{CT}$ & 23 & 25 & $0.65(0.28-1.5)$ & $0.78(0.48-1.27)$ \\
\hline TT & 4 & 3 & $0.45(0.09-2.28)$ & $0.66(0.31-1.39)$ \\
\hline Pleural effusion & Yes & No & & \\
\hline $\mathrm{CC}$ & 4 & 41 & $\operatorname{Ref}(1)$ & \\
\hline $\mathrm{CT}$ & 10 & 38 & $0.37(0.10-1.28)$ & $0.42(0.14-1.26)$ \\
\hline $\mathrm{TT}$ & 1 & 6 & $0.58(0.05-6.15)$ & $0.62(0.08-4.79)$ \\
\hline
\end{tabular}

2 (moderately differentiated) includes $41 \%$ and grade 3 (Poorly differentiated) includes $35 \%$ cases. We included smoker $45 \%$ as well as non smoker $55 \%$ with different smoking type as cigarette, bidi, and hukka, $18 \%$ cases smoked cigarette, $16 \%$ cases smoked bidi and $11 \%$ cases smoked hukka.

\section{Case-control genotype distribution}

This study observed that high percentage of CT $(48 \%)$ and TT $(7 \%)$ genotype was found in patients compared to controls CT (26\%) and TT (3\%) genotype while lower CC (45\%) genotype in patients compared to control CC (71\%) genotype. The genotype and allele distributions of NQO1 (C609T) in cases and controls are summarized in Table 2 and 4 . We observed a statistically significant difference in the frequencies of NQO1 CC, CT and TT genotypes among patients and healthy controls $(p=0.0009)$. The frequency of $\mathrm{C}$ allele (fC) was found to be lower among NSCLC patients (0.69) whereas, the higher frequency of $\mathrm{C}$ allele (fC) was observed among healthy controls (0.84). However frequency of T allele (fT) was found to be higher among NSCLC patients $(0.31)$ whereas, the lower frequency of $\mathrm{T}$ allele (fT) was observed among healthy controls $(0.16)$.

\section{NQO1 (C609T) polymorphism and NSCLC risk}

Odds ratio and risk ratio with $95 \%$ confidence intervals was calculated for each group to estimate the degree of association between the NQO1 (C609T) genotype and risk of NSCLC in Indian patients depicted in Table 3 and 5. Compared to the CC genotype, the OR 2.91(1.58-5.34) and 3.68(0.90-14.98), RR 1.74(1.23-2.44) and 2.04(0.78-5.31) for the heterozygous CT and homozygous TT genotypes were estimated, suggesting a possible dominant effect of this polymorphism on NSCLC risk.

NQO1 (C609T) genotypes and survival analysis: Survival analysis was based on the population of 100 NSCLC (Adenocarcinoma) patients. Patients with CC genotype showed 13 months of overall median survival time, Patients with TT genotype showed 8.2 months of overall median survival time while patients with CT genotype showed 6 months of median survival time. When survival calculated together CT + TT genotype also showed 6.35 months of median survival time in comparison of $\mathrm{CC}$ genotype and found to be significantly associated $(p=0.03)$. Patients with heterozygosity $(C T)$ exhibited a significant poor overall survival and found to be significantly associated $(\mathrm{p}=0.02)$ (Figure $2 \mathrm{a}, \mathrm{b})$. 


\section{Discussion}

NAD (P)H: oxidoreductase (NQO1) is also an important enzyme in xenobiotic metabolism that catalyzes the two electron reduction of carcinogenic quinoid compound to their reduced form such as quinones (Nebert et al., 2002). The activity of NQO1 enzyme depends on polymorphisms at the NQO1 locus. The major polymorphism is $\mathrm{C}$ to $\mathrm{T}$ substitution at nucleotide 609 of exon 6 resulting in the Proline to Serine amino acid substitution Pro187Ser has previously been reported to reduce quinone reductase activity in vitro (Siegel et al., 2001). The present case-control study of 100 subjects explored the association of NQO1 (C609T) functional polymorphism with risk and prognosis of NSCLC in Indian population. Our results suggest that homozygous NQO1 609TT genotype as the risk of developing NSCLC with approximately more than 3.6fold increase while heterozygous NQO1 609CT genotype also showed approximately more than 2.9-fold increase than homozygous NQO1 609CC genotype, and were an independent prognostic marker of unfavourable clinical outcome of NSCLC patients. Patients with homozygous TT and heterozygous CT genotype had a higher risk for death than homozygous CC genotype. Patients with heterozygous genotype had at intermediate risk it was observed that 2.04 and 1.74 fold higher risk was observed with TT and CT genotype respectively [table 3]. It was also observed that high $\mathrm{T}(0.31)$ allele frequency in case compared to control $(0.16)$. To the best of our knowledge, this is the first study report of genetic association of NQO1 (C609T) polymorphism with the NSCLC risk and prognosis, confirming the possible role of NQO1 gene in the pathogenesis of NSCLC malignancy. NQO1 has been involved to stabilize the 533 tumour suppressor protein by inhibiting its degradation through a direct protein-protein interaction (Asher et al., 2001; Anwar et al., 2003). NQO1 $\mathrm{C}$ to $\mathrm{T}$ substitution results in poor enzymatic activity and no detectable protein as shown in individuals homozygous for the T allele (Traver et al., 1997). NQO1 variant T allele has been suggested to be a risk factor for lung cancer in Caucasians population (Rosvold et al., 1995; Lewis et al., 2001) and $\mathrm{Xu}$ et al. found that both the $\mathrm{C} / \mathrm{T}$ and $\mathrm{T} / \mathrm{T}$ genotype produced a higher risk of lung cancer compared with the wild-type genotype (C/C) (Xu LL et al., 2001). NQO1 C to T (C609T) polymorphism results in Proline to Serine amino acid substitution at position 187 (P187S). This substitution results to an extremely unstable NQO1 protein which is rapidly ubiquitinated and degraded by the proteasome (Siegel et al., 2001). It has been found C609T polymorphism is associated with an increased risk for several malignancies, eg, colorectal cancer, breast cancer, lung cancer, and bladder cancer (Chen et al., 1999; Chao et al., 2006; Yuan et al., 2011) while Hamajima et al also suggested that the CC genotype of the NQO1 C609T polymorphism is associated with increased risk of lung cancer, and the TT genotype increases the risk of lung cancers and esophagus cancer (Hamajima et al., 2002). Among patients who developed tumours, induced by chemical carcinogens such as urothelial cancer, renal cancer (Schulz et al., 1997) and leukemias (Wiemels et al.,
1999; Larson et al., 1999) the NQO1 609T allele has been found more frequently than among controls. According to Ren et al. (2006). NQO1 C609T in gastric cancer patients is higher than the controls. Individuals with NQO1 (T/C) and NQO1 (T/T) genotypes have higher onset risk with odds ratios of 2.08 and 3.81 respectively (Ren et al., 2006). $\mathrm{Su}$ et al. (2012) found that the frequency of NQO1 (T/T) was increased in colon cancer patients with the increased malignance, and the patients with NQO1 (T/T) had higher onset risk to develop colon cancer in well-differentiated, moderately-differentiated and poorly-differentiated colon cancer (Su et al., 2012). According to Kolesar JM NQO1 $* 2 / * 2$ is associated with poor survival in non-small cell lung cancer patients (Kolesar et al., 2011). Mei-Miao Chiu et al. (2009) also found that Immuno - histochemical examination showed that the significant increase of NQO1 protein was only found in the tumour specimens with wild type CC genotype but weak or no NQO1 protein immunoreactivity was detected in nonneoplastic liver tissue, as well as in HCC tumor tissue in individuals carrying the heterozygous CT genotype (Mei-Miao Chiu et al., 2009).

Conclusion: Present study conclude that NQO1 (C609T) polymorphism contributes to risk of developing NSCLC and heterozygous CT and TT genotype may be associated with higher risk for unfavorable clinical outcome of NSCLC patients. In addition, NQO1 CT and TT genotype also associated with poor survival of Non small cell lung adenocarcinoma patients. Due to the small sample size in the present study, our findings need to be validated by further independent and prospective studies on a larger population.

\section{Acknowledgements}

The authors thank to all the study subjects and All India Institute of Medical Sciences, New Delhi, for assistance in recruiting the subjects.

\section{References}

Anwar A, Dehn D, Siegel D, et al (2003). Interaction of human NAD (P)H:quinone oxidoreductase 1 (NQO1) with the tumor suppressor protein $\mathrm{p} 53$ in cells and cell-free systems. J Biol Chem, 278, 10368-73.

Asher G, Lotem J, Cohen B, et al (2001). Regulation of p53 stability and $\mathrm{p} 53$-dependent apoptosis by NADH quinone oxidoreductase 1. Proc Natl Acad Sci USA, 98, 1188-93.

Chao C, Zhang ZF, Berthiller J, et al (2006). NAD(P)H:Quinone Oxidoreductase 1 (NQO1) Pro187Ser polymorphism and the risk of lung, bladder, and colorectal cancers: a meta-analysis . Cancer Epidemiol Biomarkers Prev, 15, 979-87.

Chen H, Lum A, Seifried A, et al (1999). Association of the NAD (P) H: Quinone oxidoreductase 609CT polymorphism with a decreased lung cancer risk. Cancer Res, 59, 3045-8.

Chen J, Lin Y, Zhang R, et al (2012). Contribution of NAD(P)H quinone oxidoreductase 1 (NQO1) Pro187Ser polymorphism and risk of colorectal adenoma and colorectal cancer in Caucasians: a meta-analysis. Arch Med Res, 43, 58-66.

Guha N, Chang JS, Chokkalingam AP, et al (2008). NQO1 polymorphisms and de novo childhood leukemia: a HuGE review and meta-analysis. Am J Epidemiol, 168, 1221-32.

Hamajima N, Matsuo K, Iwata H, et al (2002). NAD(P)H: 
quinone oxidoreductase 1 (NQO1) C609T polymorphism and the risk of eight cancers for Japanese. Int J Clin Oncol, 7, 103-8.

Haruya K, Nobuyuki H, Akiko T, et al (2003). Triplex polymerase chain reactions with confronting two-pair primers (PCR-CTPP) for NQO1 C609T, GSTM1 and GSTT1 polymorphisms: a convenient genotyping method.

Hou L, Chatterjee N, Huang W, et al (2005). CYP1A1 Val462 and NQO1 Ser187 polymorphisms, cigarette use and risk for colorectal adenoma. Carcinogenesis, 26, 1122-8.

Kolesar JM, Dahlberg SE, Marsh S, et al (2011). The NQO1*2/*2 polymorphism is associated with poor overall survival in patients following resection of stages II and IIIa non-small cell lung cancer. Oncol Rep, 25, 1765-72.

Larson RA, Wang X, Banerjee M, et al (1999). Prevalence of the inactivating $609 \mathrm{C}$ to $\mathrm{T}$ polymorphism in the $\mathrm{NAD}(\mathrm{P})$ $\mathrm{H}$ : quinone oxidoreductase (NQO1) gene in patients with primary and therapy-related myeloid leukemia. Blood, 94, 803-7.

Lewis SJ, Cherry NM, Niven RM, et al (2001). Polymorphisms in theNAD( $\mathrm{P}) \mathrm{H}$ : quinine oxidoreductase gene and small cell lung cancer risk in a UK population. Lung Cancer, 34, $177-83$

Mei-Miao C, Ying-Ju K, Ann-Ping T, et al (2009). Analysis of NQO1 polymorphisms and p53 protein expression in patients with hepatocellular carcinoma. Histol Histopathol, 24, 1223-32.

Menashe I, Figueroa JD, Garcia-Closas M, et al (2012). Largescale pathwaybased analysis of bladder cancer genome-wide association data from five studies of European background. PLoS One, 7, 29396.

Nebert DW, Roe AL, Vandale SE, et al (2002). NAD (P) $\mathrm{H}$ :quinine oxidoreductase (NQO1) polymorphism, exposure to benzene, and predisposition to disease: a HuGE review. Genet Med, 4, 62-70.

Ren JJ, OuYang XH, Su XL (2006). NAD (P)H:quinone oxidoreductase gene polymorphism association with gastric carcinoma. Zhong Hua Zhong liu Fang Zhi Za Zhi (in Chinese), 22, 1686-8.

Ross D (2004). NQO1. Atlas genet cytogenet oncol haematol. URL : http://AtlasGeneticsOncology.org / Genes / NQO1ID375.html.

Rosvold EA, McGlynn KA, Lustbader ED, et al (1995). Identification of an NAD (P) H: quinone oxidor - eductase polymorphism and its association with lung cancer and smoking. Pharmacogenetics, 5, 199.

Sarmanova J, Susova S, Gut I, et al (2004). Breast cancer: role of polymorphisms in biotransformation enzymes. Eur J Hum Gen, 12, 848-54.

Schulz WA, Krummeck A, Rosinger I, et al (1997). Increased frequency of a null-allele for $\mathrm{NAD}(\mathrm{P}) \mathrm{H}$ : quinone oxidoreductase in patients with urological malignancies. Pharmacogenetics, 7, 235-9.

Siegel D, Anwar A, Winski SL, et al (2001). Rapid polyubiquitination and proteasomal degradation of a mutant form of NAD (P)H:quinone oxidoreductase 1. Mol Pharmacol, 59, 263-8.

Su XL, Yan MR, Yang L, et al (2012). NQO1 C609T polymorphism correlated to colon cancer risk in farmers from western region of Inner Mongolia. Chin J Cancer Res, 24, 317-322.

Traver RD, Siegel D, Beall HD, et al (1997). Characterization of a polymorphism in $\mathrm{NAD}(\mathrm{P}) \mathrm{H}$ : quinone oxidoreductase (DT-diaphorase). Br J Cancer, 75, 69-75.

Wiemels JL, Pagnamenta A, Taylor GM, et al (1999). United Kingdom Childhood Cancer Study Investigators. A lack of a functional $\mathrm{NAD}(\mathrm{P}) \mathrm{H}$ : quinine oxidoreductase allele is selectively associated with pediatric leukemias that have MLL fusions. Cancer Res, 59, 4095-9.

Xu LL, Wain JC, Miller DP, et al (2001). The NAD (P) H: quinone Oxidoreductase 1 Gene Polymorphism and Lung Cancer Differential Susceptibility Based on Smoking Behavior. Cancer Epidemiol Biomarkers Prev, 10, 303-9.

Yuan W, Xu L, Chen W, et al (2011). Evidence on the association between NQO1 Pro187Ser polymorphism and breast cancer risk in the current studies: a meta-analysis. Breast Cancer Res Treat, 125, 467-72. 